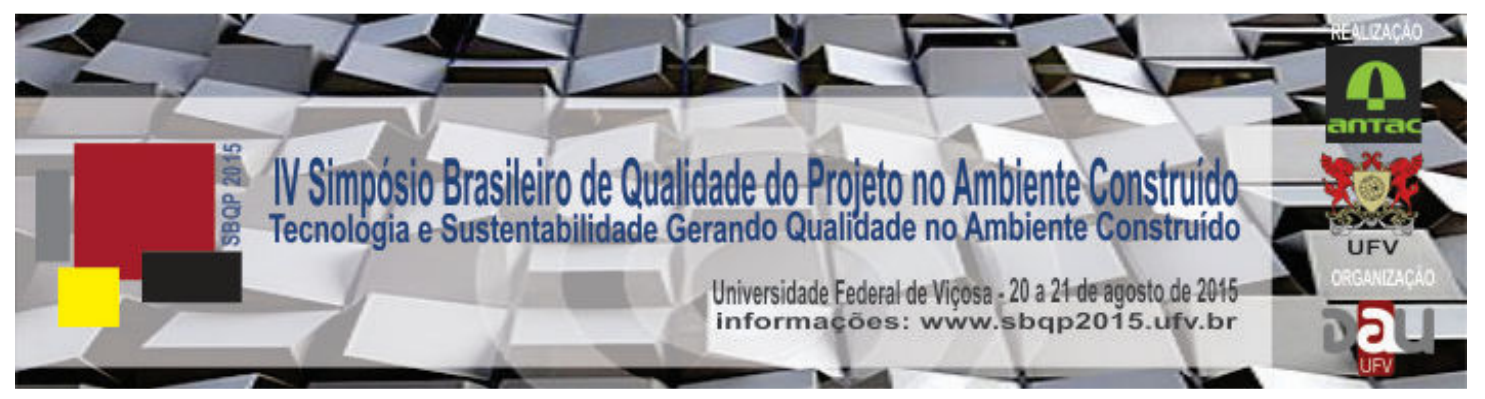

\title{
CONTRIBUIÇÕES PARA ESTUDO DO MINHA CASA MINHA VIDA PARA UMA CIDADE DE PORTE MÉDIO: PELOTAS-RS1
}

\author{
PINTO, Jones Vieira \\ Universidade Federal de Pelotas, e-mail: jonesvieirapinto@hotmail.com \\ MEDVEDOVSKI, Nirce Saffer \\ Universidade Federal de Pelotas, e-mail: nirce.sul@gmail.com
}

\begin{abstract}
RESUMO
Este trabalho visa contribuir para a caracterização dos agentes privados produtores dos empreendimentos Minha Casa Minha Vida (MCMV) em Pelotas-RS. Esta cidade de porte médio coloca-se no ranking do déficit habitacional absoluto como a $106^{\mathrm{a}}$ entre 5.570 municípios de todo o país. Apresenta o cenário local, comparando a produção de Habitação de Interesse Social, sob a égide do Programa MCMV com a do programa habitacional anterior - Programa de Arrendamento Residencial - PAR, programa em que Pelotas também se destacou pela produção de mais de 3.000 unidades. Neste relato, são identificadas as construtoras que atuam e atuaram na cidade, caracterizando sua origem, estratégia de localização, tipologia e número de unidades produzidas. Utiliza como métodos a revisão da bibliografia recente sobre o MCMV no país, a confecção e análise de um banco de dados dos empreendimentos já edificados em Pelotas, aprovados junto à CAIXA e Banco do Brasil nos dois Programas e entrevista com o atual presidente do sindicato da Indústria da Construção Civil de Pelotas. Foi identificada a atuação de somente um agente promotor de fora da cidade, participante do processo de abertura de capital no mercado financeiro. Constata-se a supremacia das construtoras locais sobre as de fora no total de unidades produzidas. Conclui pela diferenciação clara das estratégias entre empresas de grande porte (de fora da cidade), que atuam nas faixas superiores do PMCMV e não atuaram no PAR, e empresas de portes médio e pequeno, que atuam e atuaram nos dois Programas. Estas últimas buscam a Faixa 1, onde o terreno é viabilizado pelo poder público municipal assim como o consumidor final, bem como promovem empreendimentos de menor porte na Faixa 2. A empresa de atuação nacional busca grandes áreas e parcerias com imobiliárias locais. Constata-se a semelhança destas estratégias em outras cidades de porte médio junto à bibliografia recente.
\end{abstract}

Palavras-chave: Programa Minha Casa Minha Vida, Produção habitacional, Habitação de Interesse Social.

\begin{abstract}
This work aims to contribute for the characterization of private agents responsible for the Minha Casa Minha Vida - "My House My Life" (MCMV) enterprises in the city of
\end{abstract}

1 Trabalho apresentado no IV SBQP 2015. Universidade Federal de Viçosa.

Disponível em: doi> http://dx.doi.org/10.18540/2176-4549.6032 
Pelotas-RS. This middle-size city is found as the 106th in the absolute housing shortage ranking among 5,570 towns all over the country. It presents a local scenario, comparing the production of Social Interest Housing, under the aegis of the MCMV Program with the one from the previous housing program - Programa de Arrendamento Residencial (Residential Lease Program) - PAR, which reached a highlight in the city of Pelotas due to the construction of over 3,000 units. In the present report, the construction companies which work and worked in the city are identified, characterizing their origin, location strategy, typology and number of units produced. It uses the recent bibliographic review on the MCMV in the country, the confection and analysis of data bank of enterprises already built in Pelotas, approved by CAIXA and Banco do Brasil in the two Programs and interview with the present Civil Construction Industry Union from Pelotas as methods. The work of only one promoting agent who was also a participant in the opening process of capital in the financial market has been noticed. This agent is not from the city. The supremacy of local construction companies over others is noticed in the whole of the units produced. It is then concluded due to the clear differentiation of strategies between large companies (from out of the city), which work in the higher levels of the PMCMV and did not work in the PAR, and medium-size and small companies, which work and worked in both Programs. The latter ones aim at the Level 1, where the land is made possible by the municipal public power as well as by the final consumer, and promote enterprises of smaller scale in the Level 2. The national scale company seeks large areas and partnerships with local realtors. The similarity of these strategies is noticed in other middle-size cities as found in recent bibliography.

Keywords: Program Minha Casa Minha Vida, Housing production, Social Interest Housing.

\section{INTRODUÇÃO}

Com o crescente aumento populacional e consequentemente aumento do déficit, os rumos da política habitacional brasileira passaram por inúmeras mudanças ao longo das últimas décadas, mas especialmente a partir dos anos 2000, duas formas de promoção de habitação social vigoraram fortemente no país, sendo a primeira caracterizada pela promoção de habitação por arrendamento da moradia, onde a família beneficiada ficava atrelada ao imóvel por um período determinado de tempo - Programa de Arrendamento Residencial (PAR) -, e outra que se deu através de incentivos do governo por meio de subsídios e ampla abertura de crédito para a compra da casa própria - Programa Minha Casa Minha Vida (PMCMV) (MEDVEDOVSKI, 2009; CHIARELLI, 2014).

Este trabalho caracteriza o modo como atuam as empresas no MCMV, assim como atuaram no PAR, em uma cidade de porte médio - Pelotas. Identifica suas características e estabelece perfis de empresas e seus respectivos nichos dentro dos PMCMV e PAR. Também identifica as características da produção dos dois períodos, identificando os agentes públicos e privados, as formas de contratação e concepção do produto e as tipologias e porte das unidades ofertadas.

\section{OBJETIVOS}

Esclarecer as diferentes estratégias das empresas do setor da construção na resposta aos dois Programas - PAR e PMCMV -, identificando essas diferenças nos resultados de suas operações, caracterizadas por números de unidades, faixas de mercado, tipologias de parcelamento do solo e localização. Também traçar um comparativo com o perfil do mercado encontrado em 
outra cidade de porte médio do país por pesquisa já realizada, para os agentes privados promotores do PMCMV.

\section{METODOLOGIA}

Como métodos para alcançar os resultados, revisou-se a literatura sobre as características e panorama atual do PMCMV. Em paralelo fez-se um levantamento, com dados do Núcleo de Pesquisa em Arquitetura e Urbanismo - UFPel (NAUrb/UFPel) (2014), Chiarelli (2014), Caixa Econômica Federal REDUR Pelotas (REDUR) (2014) e Diário Popular (2003), da listagem total de empreendimentos PAR e PMCMV em Pelotas, assim como demais características dos empreendimentos: construtora, número de unidades, número de pavimentos, localização e faixa a qual se destina $o$ empreendimento (no caso do PMCMV).

Complementando o banco de dados, para a criação de um perfil para esses agentes, foram identificadas as seguintes variáveis: local de origem, faixa de renda de maior atuação, porte de seus empreendimentos, abrangência territorial e tradição na incorporação de HIS. Também foi realizada entrevista com o atual presidente do sindicato dos construtores civis de Pelotas, para levantamento de informações qualitativas do tema.

\section{BREVE CARACTERIZAÇÃO DOS PROGRAMAS MCMV E PAR}

\subsection{Breve caracterização do PAR}

O PAR foi instituído através da Lei 10.188, de 12/02/2001, tendo como característica a construção de moradias para famílias com renda de até seis salários mínimos, onde as mesmas arrendariam estas moradias por um período de 180 meses ( 15 anos), amortizando em parcelas mensais o pagamento de seu imóvel, e após, teriam o direito de adquirir o título de propriedade da moradia. Uma espécie de "locação social", cuja ideia já havia começado no governo do presidente Fernando Henrique Cardoso, em 1996, porém não se caracterizando como este Programa propriamente dito (CHIARELLI, 2014).

O PAR, de certa forma rompeu com força os modelos de produção habitacional anteriores, sobretudo quanto ao aspecto econômico de promoção da habitação. Enquanto no período do Banco Nacional da Habitação (BNH) o Estado regia com mão forte a política habitacional através de um banco próprio - BNH, após, um período sem o aparecimento de um grande programa habitacional - de 1987 a 2000 - o neoliberalismo declarado fez com que o Estado se retirasse do cenário da Habitação de Interesse Social $(H I S)$, relegando o processo de concessão de crédito às leis de oferta e demanda do mercado (ARANTES, 2010). Em 2001 o PAR traz o subsídio habitacional ao mercado de arrendamento, numa tentativa de atender a parcela do déficit que apresentava ônus excessivo de aluguel. O mutuário poderia usufruir o imóvel de imediato, pagando um valor equivalente ao aluguel.

Em Pelotas a produção habitacional do PAR chegou a 18 empreendimentos e 3.177 unidades habitacionais, totalizando mais de $160.000 \mathrm{~m}^{2}$ de área total construída. Em termos de agentes promotores privados, as construções se deram por quatro empresas diferentes - Ricardo Ramos, Labore, Conkretus e 
Roberto Ferreira, todas estas com origem na cidade (MEDVEDOVSKI, 2009; CHIARELLI, 2014; NAURB/UFPEL, 2014).

Pelotas destacou-se no cenário nacional com uma grande produtividade, se ponderado o seu tamanho populacional no comparativo às demais cidades, fator este que se repete no PMCMV. Este fato foi atribuído à organização do Sindicato da Construção Civil - SINDUSCON local, à iniciativa da gerência local da CAIXA que incentivou as empresas a buscarem os recursos do PAR e da Secretaria de Habitação local, que viabilizou a aprovação dos empreendimentos e organizou a demanda.

\subsection{Breve caracterização da produção habitacional no PMCMV}

Criado em 2009 o Programa "Minha Casa, Minha Vida" (PMCMV) partiu de uma iniciativa do governo federal, em parceria com os estados e municípios. Em sua primeira fase objetivou a construção de um milhão de moradias para famílias com renda mensal de até dez salários mínimos. Atualmente encontrase em sua Fase 2, iniciada em 2011, onde o objetivo inicial foi a construção de mais dois milhões de moradias (CUNHA, 2014).

Tem como carro chefe a reformulação total da política de concessão de crédito às faixas mais carentes economicamente da sociedade, além de incentivo real aos promotores privados das habitações através de possibilidades de lucros maiores para os mesmos. Para a Faixa 1 do Programa famílias com renda mensal entre zero e três salários mínimos - se estabeleceu a garantia de demanda total, sem necessidade de promoção de vendas da produção (CUNHA, 2014).

O Brasil objetivava criar uma medida anticíclica de fomento à geração de empregos locais, portanto agiu em um setor extremamente manufaturado da economia - construção civil. Ainda ampliou a oferta de moradias às pessoas que não teriam condições de contrair financiamentos, utilizando-se de uma política de subsídios, e empregou o discurso do enfrentamento do déficit habitacional da época ( $8,83 \%$ de domicílios no país) como justificativa para os novos programas (IPEA, 2013).

Dentro deste contexto de uma série de fatores confluentes o PMCMV se caracteriza como um programa de alta produtividade habitacional, porém, assim como os anteriores (ou até com maior intensidade), não aplica os princípios de direito à moradia e à cidade, preconizados no Estatuto das Cidades.

\section{CARACTERIZAÇÃO DAS EMPRESAS PRODUTORAS DO PAR E PMCMV}

\subsection{Agentes promotores privados do PAR e MCMV}

Como forma de caracterização das diferenças encontradas entre as empresas produtoras dos dois Programas, buscou-se traçar um paralelo entre as mesmas quanto às suas origens, estratégias tecnológicas de produção, origens de seu capital, atuação no mercado imobiliário para faixas de renda superiores aos programas de habitação social, entre outras características.

Para tanto, os Quadros 1 e 2 apresentam a quantificação e representatividade total de cada empresa dentro do PAR e do PMCMV. 


\begin{tabular}{|c|c|c|c|c|}
\hline Construtora & $\begin{array}{c}\mathrm{N}^{\circ} \\
\text { Empreendim. }\end{array}$ & $\begin{array}{c}\text { Perc. Empreend. } \\
\text { por Construtora } \\
(\%)\end{array}$ & $\begin{array}{l}\text { No Unid. } \\
\text { Habitac. }\end{array}$ & $\begin{array}{l}\text { Perc. } N^{\circ} \text { Unid. } \\
\text { Habitacionais por } \\
\text { Construtora (\%) }\end{array}$ \\
\hline Roberto Ferreira & 5 & 27,78 & 966 & 30,41 \\
\hline Ricardo Ramos & 5 & 27,78 & 892 & 28,08 \\
\hline Labore & 5 & 27,78 & 819 & 25,78 \\
\hline Conkretus & 3 & 16,67 & 500 & 15,74 \\
\hline TOTAL & 18 & 100,00 & 3.177 & 100,00 \\
\hline
\end{tabular}

Fonte: Chiarelli (2014); NAUrb/UFPel (2014)

\section{Quadro 2 - Empreendimentos e Unid. Habitacionais por Construtora - PAR}

\begin{tabular}{|c|c|c|c|c|}
\hline Construtora & $\begin{array}{c}\mathbf{N}^{\circ} \\
\text { Empreendim. }\end{array}$ & $\begin{array}{l}\text { Perc. Empreend. } \\
\text { por Construtora } \\
(\%)\end{array}$ & $\begin{array}{l}\text { No Unid. } \\
\text { Habitac. }\end{array}$ & $\begin{array}{l}\text { Perc. N Unid. } \\
\text { Habitacionais por } \\
\text { Construtora (\%) }\end{array}$ \\
\hline Ricardo Ramos & 11 & 21,57 & 2.380 & 25,73 \\
\hline Rodobens & 5 & 9,80 & 2.470 & 26,70 \\
\hline Roberto Ferreira & 7 & 13,73 & 1.096 & 11,85 \\
\hline Labore & 4 & 7,84 & 940 & 10,16 \\
\hline Serial & 6 & 11,76 & 757 & 8,18 \\
\hline Zechlinski & 3 & 5,88 & 556 & 6,01 \\
\hline SPO & 4 & 7,84 & 398 & 4,30 \\
\hline ACPO & 2 & 3,92 & 171 & 1,85 \\
\hline $\begin{array}{l}\text { SPE Village } \\
\text { Center IV }\end{array}$ & 2 & 3,92 & 120 & 1,30 \\
\hline SPE Fragata & 1 & 1,96 & 120 & 1,30 \\
\hline Olavo Rocha & 2 & 3,92 & 88 & 0,95 \\
\hline MGM & 1 & 1,96 & 60 & 0,65 \\
\hline Navarini & 1 & 1,96 & 53 & 0,57 \\
\hline Solum & 2 & 3,92 & 42 & 0,45 \\
\hline TOTAL & 51 & 100,00 & 9.251 & 100,00 \\
\hline
\end{tabular}

Fonte: NAUrb/UFPel (2014)

Destaca-se que de todos os empreendimentos aprovados, somente um MCMV Faixa 1 se dá sob a modalidade de loteamento. Todos os demais adotam a forma de condomínio fechado. De acordo com a representatividade de algumas empresas apresentadas nos Quadros acima, se pesquisou as principais características das de maior produção a fim de entender o contexto de inserção das mesmas. 
Por parte do PAR, escolheu-se a empresa Roberto Ferreira, maior produtora de unidades habitacionais e empreendimentos no PAR, assim como uma das três empresas que ainda permanece no PMCMV, e por parte do PMCMV a empresa Rodobens - única, porém representativa, empresa incorporadora de empreendimentos do PMCMV em Pelotas, que não tem suas origens na cidade.

A empresa Roberto Ferreira tem sua origem em Pelotas, sendo fundada em 1953. Dentre as grandes obras na cidade, tem alguns empreendimentos fabris para outras empresas, além da estação rodoviária. Atua na construção civil, mas com predominância no setor habitacional. Seu histórico já apresenta a construção de mais de $1.000 .000 \mathrm{~m}^{2}$ de área construída, sendo um de seus objetivos a inovação constante de seus sistemas e processos construtivos, como no caso dos empreendimentos PAR, sendo de sua iniciativa a tomada da decisão da implantação da alvenaria estrutural em grande parte dos conjuntos edificados, ou como no PMCMV, onde inovou ao colocar placas fotovoltaicas nos telhados das edificações, para geração de energia aos moradores do loteamento Eldorado, ou no sistema construtivo do Residencial Haragano, onde o mesmo foi edificado com a tecnologia "Wood frame", duas técnicas inovadoras na cidade de Pelotas, em termos de HIS.

Quanto à Rodobens - Rodobens Negócios Imobiliários S.A., esta tem o seu capital aberto desde 2007, portanto participante da Bolsa de Mercadorias e Futuros do estado de São Paulo (BMeFBOVESPA). Segundo seu portal eletrônico tem atuação em 12 estados - São Paulo, Santa Catarina, Goiás, Mato Grosso, Rio Grande do Sul, Minas Gerais, Bahia, Paraná, Ceará, Pará, Mato Grosso do Sul e Rio de Janeiro, por ordem decrescente de porte da atuação - e já lançou 161 empreendimentos, construindo 61 mil unidades e 5,2 milhões de $\mathrm{m}^{2}$. Faz parte do grupo de empresas Rodobens - que está entre os 100 maiores grupos empresariais do Brasil, sendo a trigésima primeira maior construtora do país - fundado em 1949, na cidade de São José do Rio Preto-SP (CUNHA, 2014; ITC, 2014).

Atua também fora da faixa de produtos MCMV, sendo apresentados em seu portal eletrônico 31 edifícios em altura com valores de venda superiores à Faixa 3 do Programa, logo não passíveis de financiamento dentro desta linha de crédito.

Quanto a empreendimentos similares aos cinco encontrados em Pelotas, no que tange técnica construtiva, porte das moradias e arranjo das mesmas no formato de condomínio e com pequena área destinada ao lazer, esta já produziu 89 condomínios espalhados pelo país. Estabelece uma produção padronizada, com sistema construtivo único, projeto arquitetônico padrão, tamanhos mínimos dos empreendimentos, e programação visual e projeto padrão das portarias.

\subsection{Demais fatores de diferenciação dos Programas}

Em comum estes dois Programas têm a consolidação das empresas privadas incorporadoras de empreendimentos habitacionais como os grandes agentes executores da política habitacional desta e da última década. Porém no PMCMV o governo delegou ainda mais à iniciativa privada as regras de implantação e decisões dos rumos da construção de habitação social (CARDOSO, JUNIOR, ARÚJO, SILVA E JAENISCH, 2013). 
Ainda assim há diferenças nos modelos que caracterizam estes agentes. Enquanto no PAR, quatro foram as empresas promotoras, todas locais, das mais de 3.000 unidades habitacionais edificadas na cidade, no PMCMV, até julho de 2014, atuaram 13 empresas, sendo que uma delas de abrangência nacional. Das quatro empresas do PAR, três continuam a produzir empreendimentos no PMCMV - Ricardo Ramos, Labore e Roberto Ferreira.

No PAR com exceção de três empreendimentos, todos os demais foram construídos com um número máximo de 180 unidades habitacionais, ao passo que no PMCMV têm-se cinco empreendimentos com mais de 430 unidades. Quatro destes cinco empreendimentos foram desenvolvidos pela empresa de atuação no território nacional. Daí depreende-se uma característica de diferenciação das empresas locais das nacionais: o porte dos empreendimentos.

Cunha (2014) identificou situação semelhante ocorrida em São José do Rio Preto-SP, onde estudou três empresas atuantes na cidade, no PMCMV, em que duas são caracterizadas por maior abrangência, inclusive em outros estados, e a última de abrangência apenas no estado de São Paulo. Uma das empresas de abrangência nacional é a mesma que vem atuando em Pelotas Rodobens, supracitada. Afirmou que enquanto as duas empresas de abrangência nacional estudadas têm capacidade para aplicar técnicas racionalizadas de produção da habitação em série de moradias, como paredes de concreto moldadas "in loco", pois possuem empreendimentos em número e porte suficientes para a produção seriada e com maior investimento inicial, a terceira empresa, que incorpora um número menor de conjuntos e com porte menor, não é capaz de aplicar tais técnicas de seriação.

Uma hipótese do motivo que Pelotas tornou-se um atrativo para os investimentos em HIS pode ser encontrada em sua posição no "ranking" do déficit habitacional absoluto calculado pelo IPEA (2013). A cidade ocupa a $106^{a}$ posição num total de 5.570 municípios do país. Ou seja, o número de 8.274 unidades concentrado no déficit por ônus de aluguel e coabitação (PLHIS, 2013), aliado à perspectiva de desenvolvimento da indústria naval na região e a disposição de crédito, coloca a cidade na lista de interesses das empresas como a Rodobens.

Porém, quanto às demais incorporadoras de abrangência nacional, que se estabeleceram em outras cidades de porte semelhante a Pelotas em outras regiões do Brasil, quais seriam os motivos que fizeram com que as mesmas não tenham vindo e se estabelecido em Pelotas, para produzir empreendimentos semelhantes aos da Rodobens (maiores, e com maior demanda de infraestrutura e organização laboral)? A resposta a este questionamento foi buscada na forma como as empresas locais se organizaram, desde a época do PAR até os dias atuais, quanto à concorrência externa de empresas de maior porte.

Segundo o atual presidente do Sindicato da Indústria da Construção Civil de Pelotas (SINDUSCON), Eng. Ricardo Ferreira, não houve qualquer bloqueio por parte das empresas da cidade para com as de fora, mas sim uma organização entre as mesmas, organização esta que começou já na época de implantação do PAR, quando as quatro construtoras que realizaram obras neste Programa se uniram no intuito de implantar uma nova técnica construtiva na cidade para habitações de cunho social - a construção com 
blocos pré- moldados. Portanto, quando uma empresa "estrangeira" tenta penetrar neste mercado, logicamente não vai contar com este apoio sinérgico das "locais", ficando mais difícil seu estabelecimento no mercado. Entretanto confirma que houve uma pressão por parte de políticos locais e do poder público municipal junto à CAIXA e Banco do Brasil para que os créditos fossem concedidos preferencialmente para as empresas originárias da região. A entrada da Rodobens ocorre antes do lançamento do MCMV, numa parceria com as empresas de comercialização e administração condominial, que veem uma dupla oportunidade de negócios: a venda e a gestão dos empreendimentos, aplicando a experiência adquirida na implantação dos condomínios do PAR em Pelotas. Após o estabelecimento do MCMV, a Rodobens passa a multiplicar sua capacidade de vendas, adaptando seus produtos às regras do Programa.

\section{ANÁLISES E RESULTADOS}

Nesta seção apontam-se, a partir das análises, alguns motivos que fizeram com que Pelotas tivesse um número bastante superior de empreendimentos e empresas atuantes no PMCMV em relação ao PAR, esclarecendo os arranjos do mercado habitacional pelotense.

\subsection{Porte do programa habitacional}

Enquanto no PAR Pelotas produziu, de 2001 a 2008, 3.177 unidades habitacionais distribuídas em 18 empreendimentos, no PMCMV, de 2009 até julho de 2014, já foram produzidas 9.221 unidades distribuídas por 51 empreendimentos, ou seja, números três vezes maiores ao do PAR em menor tempo. Em todo o Brasil, enquanto o PAR produziu aproximadamente 270 mil unidades (em oito anos de duração), o PMCMV contratou, até abril de 2014 quando completou cinco anos -, 3,39 milhões de unidades habitacionais, $1.155 \%$ a mais que o primeiro, fator que corrobora a ideia de garantia de continuidade da empresa que está atuando longe de seu escritório central, pois abre o leque de oportunidades de empreendimentos para construção (MEDVEDOVSKI, COSWIG, CHIARELLI e ROESLER, 2010; AGÊNCIA CAIXA DE NOTÍCIAS, 2014). Este seria o primeiro fator que fez com que empresas forasteiras não se interessassem pelo PAR em cidades como Pelotas, mas se interessassem pelo PMCMV: o montante e continuidade dos recursos.

Corroborando a afirmação, no caso da Rodobens, dos seus cinco empreendimentos implantados ou em fase de implantação na cidade, três deles são contíguos em uma região da cidade - Terra Nova, Moradas Club e Moradas Pelotas - e os outros dois são contíguos em outra região - Moradas Pelotas II e Moradas Club II -, conforme as Figuras 1 e 2, abaixo. Logo, a empresa já tinha a garantia de produção dos três empreendimentos, mesmo quando ainda só aprovara o primeiro. Os cinco conjuntos também têm implantação e técnicas construtivas bastantes semelhantes entre si, além de a comercialização de todos ter sempre sido feita em um mesmo espaço físico "showroom" localizado no centro da cidade -, e pela mesma empresa associada - corretora exclusiva de comercialização de todos os empreendimentos da construtora em Pelotas. 


\section{Figuras 1 e 2 - Imagens aéreas dos Terra Nova, Moradas Pelotas e Moradas Club e dos Moradas Pelotas II e Moradas Club II}

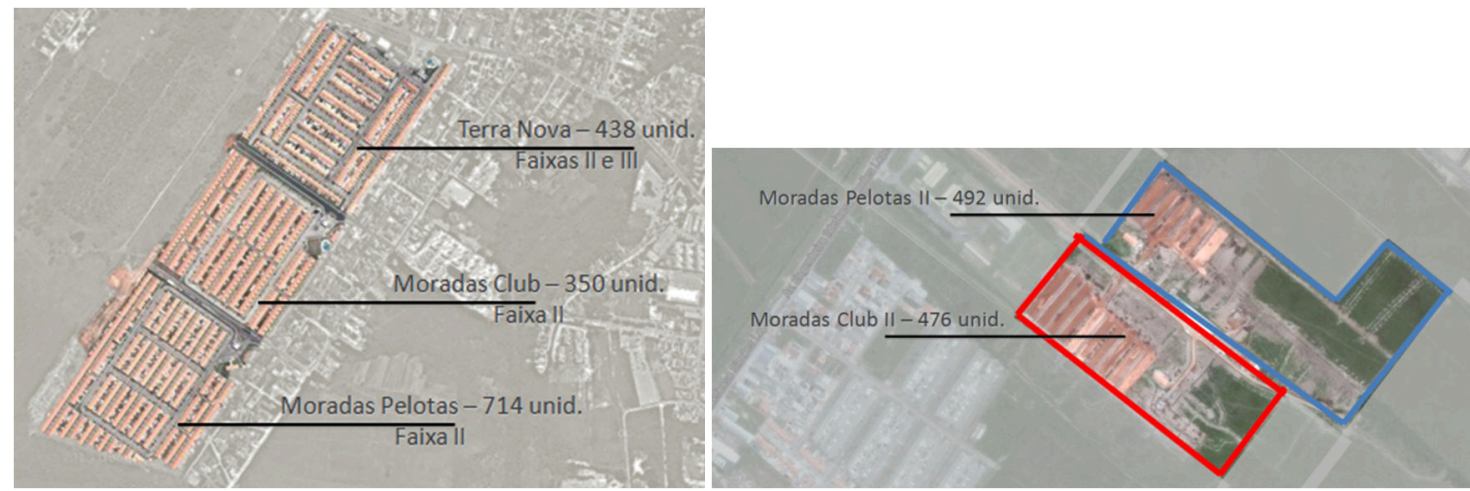

Fonte: NAUrb/UFPel (2014); Google Maps (2014); resultados da pesquisa

Em termos de números, mesmo que a empresa possua apenas cinco dos 51 empreendimentos do PMCMV, estes representam $21,97 \%$ do total de unidades habitacionais do Programa na cidade.

Além disso, Cardoso, Aragão e Araujo (2011) lembram que o lucro auferido na construção de empreendimentos pode ser aumentado quando se viabiliza a mesma em ampla escala, racionaliza-se o processo produtivo e utilizam-se novas técnicas construtivas, e que o lucro imobiliário também aumenta com a implantação de estratégia das incorporadoras de pagar menos aos proprietários de terrenos (na compra massificada, como é o caso dos terrenos da Rodobens), e na constituição de estoque de terras, prática também adotada, não somente pela Rodobens, mas por outras grandes empresas do ramo (ASBEA, 2009).

\subsection{Abrangência dos Programas}

Sobre o aspecto das faixas salariais de famílias beneficiadas pelos PAR e PMCMV, há outra diferença vital quanto à instalação ou não de empresas forasteiras na cidade de Pelotas. Enquanto o PAR abrangia famílias com até seis salários mínimos - sendo depois criado o PAR Especial, para famílias com renda de até quatro salários -, o MCMV beneficia as que recebem até dez salários mínimos.

Analisando os empreendimentos da Rodobens em Pelotas, se vê que esta só incorporou conjuntos das Faixas 2 ou 3, ou seja, sua atuação ou a atuação de empresas forasteiras, em Pelotas, na Faixa 1 do PMCMV é nula. O PAR Especial abrangia famílias com até quatro salários, e a Faixa 1 do PMCMV abrange famílias com até três (faixas similares de renda), sendo que os dois, até o momento, só têm participação de empresas locais nas construções para estas Faixas.

Cunha (2014) identifica que em São José do Rio Preto-SP as empresas de abrangência nacional produziam, primordialmente, produtos para as Faixas 2 e 3 do PMCMV, e a empresa três, atuante apenas no estado, produzia para Faixa 1. Completa que as grandes empresas vêm com um "know how" de incorporações no período anterior ao PMCMV, somente para famílias com rendas superiores. 
Já as empresas locais - de menor porte, no caso de Pelotas - já possuíam a tradição de incorporações para empreendimentos menores, devido ao mais restrito poder de suporte econômico do empreendimento. Esta tradição foi construída durante a vigência do PAR.

\subsection{Necessidade de comercialização}

Como último fator, tem-se a comercialização do produto moradia, que para a Faixa 1 do PMCMV não fica a cargo das construtoras. Em Pelotas, a Secretaria de Justiça Social e Segurança (SJSS), órgão integrante da Prefeitura Municipal, através de seu sistema de cadastramento de famílias com rendas inferiores a três salários mínimos, designa, por meio de cadastro, triagem e sorteio, quem serão os beneficiados pelos empreendimentos produzidos para a Faixa no Programa.

Depois de concluídas as obras, a empresa receberá a parcela restante do valor contratado, não tendo a responsabilidade de comercialização do mesmo, ficando a entrega das unidades ao usuário final a cargo da prefeitura. Caso haja inadimplência ou quebra de contrato por parte de uma família beneficiada, o problema não será mais da construtora, mas sim do agente financeiro e da prefeitura - o que atrai empresas menores, conferindo total liquidez ao negócio.

Já para as Faixas 2 e 3, tal comercialização fica a cargo da construtora, em parceria com seus agentes corretores, portanto seu retorno financeiro do investimento não termina quando as obras são concluídas, ficando condicionado à venda de todas as unidades.

Em contrapartida, quando se participa da etapa de comercialização de uma moradia, joga-se com uma margem maior de lucros do que quando isso já está engessado em lei e contrato, portanto as empresas maiores se sentem atraídas por esta oportunidade de conseguirem extrair um maior rendimento de seus produtos no jogo do mercado. Também praticam estratégias de valorização baseadas na renda diferencial gerada por empreendimentos sequenciais.

\section{CONCLUSÕES}

Identificamos, portanto, em Pelotas, uma segmentação de mercado que traz alternativas para todos os níveis e portes de empresas construtoras (agentes privados) envolvidas no PMCMV, confirmando assim estratégias das empresas atuantes em Pelotas muito semelhantes às encontradas por Cunha (2014) para São Jose do Rio Preto. Destacamos que a acomodação das grandes empresas ao mercado local trouxe consequências negativas para a cidade, com o desrespeito às legislações de controle do parcelamento do solo e criação de legislações casuísticas. Entretanto, seja com as empresas locais, seja com as de atuação nacional, cabe destacar a escolha preponderante pela forma de parcelamento do solo em conjunto fechado de lotes + casas, ou de condomínios de edificações coletivas, reforçando a segregação espacial e trazendo graves problemas de gestão condominial, principalmente na faixa de 0 a 3 salários mínimos.

Ainda conclui-se pelo expressivo aumento de agentes privados participantes no PMCMV em relação ao PAR, dado a diversos fatores, sendo alguns deles 0 
fluxo contínuo de financiamentos entre 2009 e 2014, a garantia que as grandes empresas precisavam para a promoção do estoque de terras já adquiridos no momento de sua abertura de capital, bem como a oferta de moradias para um consumidor com renda familiar superior ao período do PAR, constituindo as Faixas 2 e 3. Para a Faixa 1, as regras do PMCMV vão ao encontro das aspirações de empresas com menor poder de investimento, como garantia por parte do Estado de demanda e de pagamento pelos serviços prestados, imediatamente após a conclusão das obras. Este quadro permitiu a convivência das empresas construtoras locais e as de âmbito nacional, como constatado em outras cidades de médio porte. Mas em Pelotas, a herança da significativa produção no PAR e da organização do sindicato empresarial, permitiu a supremacia das construtoras locais sobre as de fora no total de unidades produzidas.

\section{REFERÊNCIAS}

AGÊNCIA CAIXA DE NOTíCIAS. Brasil Habiłação: Minha Casa Minha Vida prevê a entrega de 2 milhões de casas até o fim do ano. Caixa. Disponível em: <http://www20.caixa.gov.br/Paginas/Noticias/Noticia/Dafault.aspx? newsID=90 4> . Acesso em: 24 mar. 2015.

ARANTES, P. F. Pesquisa sobre o par apresenta antecedentes do 'Minha Casa, Minha Vida'. 17 n. 28. São Paulo dez. 2010. Disponível em: < www.revistas.usp. br/posfau/article/download/43717/47339>. Acesso em: 19 jan. 2014.

ASBEA. Notícias: Construtoras renegociam aquisições de terrenos: dívidas com ativos comprados durante o boom somam R\$ 7,7 bi. Asbea. Mai. 2009. Disponível em: http://www.asbea.org.br/escritorios-arquitetura/noticias/ construtoras-renegociam-aquisições-de-terrenos-134481-1.asp>. Acesso em: 11 mai. 2009.

CAIXA ECONÔMICA FEDERAL. Acervo com relação de empreendimentos do PMCMV em Pelotas. Dados não publicados fornecidos pela CEF em julho de 2014.

CARDOSO, A. L., ARAÚJO, F. de S., JAENISCH, S. T. Quando um direito vira produto: impactos do programa Minha Casa Minha Vida na cidade do Rio de Janeiro. In: XIII Simpósio Nacional de Geografia Urbana. Rio de Janeiro, Nov. 2013.

CARDOSO, A. L., ARAGÃO, T. A., ARAUjO, F. de S. Habitação de Interesse Social: Política ou Mercado? Reflexos sobre a construção do espaço metropolitano. In: Encontro Nacional da ANPUR, 14, 2011. Anais do XIV Encontro Nacional da ANPUR. Rio de Janeiro: ANPUR, 2011.

CHIARELLI, L. M. A. Habitação social em Pelotas (1987-2010): influência das políticas públicas na promoção de conjuntos habitacionais. 2014. 230 f. Tese (Doutorado em História) - Pontifícia Universidade Católica do Rio Grande do Sul, Porto Alegre.

CUNHA, G. R. O Programa Minha Casa Minha Vida em São José do Rio Preto/SP: Estado, Mercado, Planejamento Urbano e Habitação. 2014. 362 f. Tese (Doutorado em Arquitetura e Urbanismo) - Universidade de São Paulo, São Carlos. 
DIÁRIO POPULAR. Economia: Inscrições abertas ao PAR Especial. Diário Popular. Pelotas. Disponível em: <http//srv-net.diariopopular.com.br/07_11_03/ gm061103.html>. Acesso em: 07 nov. 2013.

FURTADO, B. A., NETO, V. C. L., KRAUSE, C. Estimativas do déficit habitacional brasileiro (2007-2011) por municípios (2010). n. 01. Brasília: IPEA, 2013.

ITC. Ranking ITC: Saiba quem são as maiores construtoras de 2014. ITC. Disponível em: http://rankingitc.com.br/ranking-itc-2014/. Acesso em: 07 mar. 2015.

MEDVEDOVSKI, N. S., CHIARELLI, L. M. Á.; ROESLER, S.; COSWIG, M. T. Inserção urbana e terceirização da gestão no projeto de empreendimentos PAR. In: $1^{\circ}$ CIHEL - Congresso Internacional da Habitação no Espaço Lusófono, 2010. Anais do $1^{\circ}$ CIHEL. Lisboa, 2010.

MEDVEDOVSKI, N. S. et al. Gerac,ão de indicadores de qualidade dos espac,os coletivos em Empreendimentos de Habitaccáo de Interesse Social. Relatório de Pesquisa Processo CNPq n. 405401/2006-0. Pelotas, 2009.

NÚCLEO DE PESQUISA EM ARQUITETURA E URBANISMO - NAURB/UFPEL. Acervo com relação de empreendimentos do PAR em Pelotas. Dados não publicados fornecidos pelo NAUrb/UFPel em out. de 2014.

PELOTAS. Prefeitura Municipal de Pelotas - PLHIS: Plano de Habitação de Pelotas: resumo do diagnóstico habitacional. Disponível em: <plhispelotas.blogspot.com>. Acesso em: 21 fev. 2014. 